Volume 4 No 2 Maret 2019

p-ISSN : 2460-8750 e-ISSN : 2615-1731

http://dx.doi.org/10.26858/talenta.v4i2.6785

\title{
HUBUNGAN OPENNESS DAN CONSCIENTIOUSNESS TERHADAP PERILAKU KERJA INOVATIF: PERAN MODERASI DARI MASA KERJA PADA PERUSAHAAN STARTUP
}

\author{
Steffira Anjani ${ }^{1}$ dan Eka Gatari ${ }^{2}$ \\ ${ }^{1,2}$ Fakultas Psikologi, Universitas Indonesia, Depok 16424, Indonesia

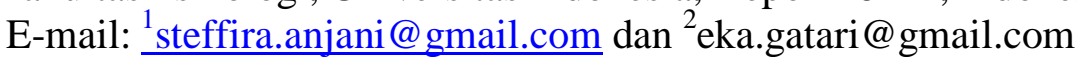

(C2019 -JPT Fakultas Psikologi Universitas Negeri Makassar. Ini adalah artikel dengan

akses terbuka di bawah licenci CC BY-NC-4.0 (https://creativecommons.org/licenses/by-nc/4.0/ ).

\begin{abstract}
Abstrack. Personality traits (openness and conscientiousness) were found to play a major role to improve innovative work behavior. However, the relationship between the two variables cannot be fully understood because of the rule of tenure as the moderator. In order to provide greater clarity, researcher wants to examine the effects of openness and conscientiousness on innovative work behavior and how the dynamic of moderating effects of tenure on the associations between traits and innovative work behavior among startup employees. Researcher has conducted a cross-sectional study on 105 startup employees. The results showed that openness and conscientiousness personality traits influenced the innovative work behavior, but there was no moderation effect of tenure to be found. Findings of this research can increase theoretical understanding and also can be used by startup companies in the recruitment and selection process to select employees who have the characteristics of openness and conscientiousness with high potential to innovate.
\end{abstract}

Keywords : Conscientiousness, Openness, Innovative Work Behaviour, Tenure

\begin{abstract}
Abstrak. Tipe kepribadian openness dan conscientiousness ditemukan berperan untuk meningkatkan perilaku kerja inovatif. Namun demikian, hubungan kedua variabel tersebut belum dapat sepenuhnya dimengerti karena adanya peran masa kerja sebagai moderator. Peneliti hendak menguji pengaruh tipe kepribadian openness dan conscientiousness pada perilaku kerja inovatif dan bagaimana dinamika dari peran masa kerja sebagai moderator pada karyawan startup. Peneliti melakukan penelitian cross-sectional pada 105 karyawan startup. Hasil penelitian menunjukkan bahwa tipe kepribadian openness dan conscientiousness memiliki pengaruh terhadap perilaku kerja inovatif, tetapi tidak ditemukan peran masa kerja sebagai moderator. Temuan penelitian dapat menambah pemahaman teoretis serta dapat digunakan oleh pihak perusahaan startup pada proses rekrutmen dan seleksi untuk memilih karyawan dengan karakteristik openness dan conscientiousness yang memiliki potensi untuk berinovasi.
\end{abstract}

Kata Kunci: Conscientiousness, Openness, Innovative Work Behaviour, Tenure

PENDAHULUAN

Era VUCA (Volatility, Uncertainty, Complexity, dan Ambiguity) merupakan masa-masa yang penuh dengan gejolak perubahan dan
(Raghuramapatruni \& Kosuri, 2017). Kondisi ini muncul karena adanya perkembangan tuntutan jaman, digitalisasi dan derasnya arus informasi sehingga 
perubahan menjadi suatu hal yang sulit untuk diprediksi (Potsangbam, 2017). Perubahan yang serba tidak pasti ini melanda seluruh lapisan yang berimbas pada berbagai segi kehidupan, termasuk pada sektor bisnis. Tren sektor bisnis yang sedang berkembang dengan pesat salah satunya adalah perusahaan startup. Startup merupakan perusahaan baru atau perusahaan rintisan yang sedang bertumbuh untuk dapat bertahan (Salamzadeh \& Kesim, 2015).

Dewasa ini, gelombang persaingan di antara perusahaan startup semakin meningkat di Indonesia. Menurut data dari StartUpRanking.com (2018), Indonesia tercatat sebagai negara ke-4 di dunia dengan jumlah startup terbanyak yaitu sebesar 1.559. Namun demikian, untuk dapat bertahan dan bersaing bukan hal yang mudah bagi perusahan startup. Survei yang dilakukan oleh TirtoId melaporkan bahwa terdapat 9 dari 10 perusahaan startup yang mengalami kegagalan (Bhaskara, 2016).

Studi dari Forbes menunjukkan bahwa kurangnya inovasi merupakan salah satu penyebab kegagalan perusahaan startup (Patel, 2015). Hasil ini menunjukkan bahwa inovasi merupakan kunci penting bagi perusahaan startup untuk dapat mempertahankan eksistensinya. Dalam rangka memenuhi kebutuhan mengikuti perubahan di era VUCA, sumber daya manusia pada perusahaan startup menjadi memiliki tuntutan agar senantiasa menampilkan perilaku kerja inovatif yang diharapkan. Sehubungan dengan isu-isu tersebut, studi mengenai perilaku kerja inovatif pada karyawan di perusahaan startup menjadi penting untuk diteliti.

Perilaku kerja inovatif merupakan intensi untuk mencipta, memproduksi dan mengaplikasikan ide-ide baru dalam bekerja sesuai peran bagi kelompok maupun organisasi yang bertujuan untuk menguntungkan pekerjaan individu, kelompok, atau organisasi (Janssen, 2000). Berdasarkan meta analisis yang dilakukan oleh Hammond, Neff, Farr, Schwall, dan Zhao (2011), perilaku kerja inovatif dipengaruhi oleh beberapa faktor dan salah satunya adalah kepribadian. Kepribadian merupakan salah satu faktor individual yang penting karena memiliki kontribusi terhadap perilaku, sikap dan kinerja seseorang di tempat kerja (Yesil \& Sozbilir, 2013). Kepribadian direpresentasikan dengan tipe kepribadian big five karena merupakan konstruk yang paling mendekati untuk menggambarkan aspek-aspek dari kepribadian individu (Kumar \& Bakshi, 2010).

Tipe kepribadian dari big five pada penelitian ini difokuskan pada openness dan conscientiousness. Berdasarkan penelitian terdahulu, kedua trait tersebut merupakan 
dua tipe kepribadian yang secara konseptual berhubungan dengan perilaku kerja inovatif dan paling konsisten terbukti secara empiris (George \& Zhou, 2001; Hammond dkk., 2011; Woods, Lievens, de Fruyt, \& Wille, 2013; Woods, Mustafa, Anderson, \& Sayer, 2018). Peneliti hendak menguji peran tipe kepribadian openness dan conscientiousness pada perilaku kerja inovatif.

Penelitian ini mereplikasi model penelitian dari Woods dkk. (2018) yang dilakukan dengan sampel karyawan dari program Management Trainee pada perusahaan jasa keuangan. Dalam penelitian ini, peneliti tertarik untuk melakukan studi serupa dengan sampel karyawan startup. Peneliti menganggap bahwa tipe kepribadian karyawan sangat penting dalam konteks perusahaan startup. Fakta pertama yang peneliti dapatkan dari Bussgang (2017) adalah dinamika kerja perusahaan startup berbeda dengan perusahaan konvensional, terutama karena perusahaan startup yang sangat dinamis dan penuh ketidakpastian. Berdasarkan hal tersebut, Bussgang (2017) menemukan bahwa startup business owner akan mencari pegawai yang memiliki kepribadian sesuai dengan entitas dari bisnis startup, selain beberapa hal umum yang diperlukan dalam mencari pegawai terbaik. Beberapa kepribadian pegawai yang penting yang dicari oleh pemilik perusahaan startup antara lain kreatif, inovatif serta memiliki fleksibilitas yang tinggi dalam mencari solusi dari permasalahan (Deen, 2017). Hal ini menunjukkan adanya kepribadian khusus yang dibutuhkan oleh calon pegawai yang bekerja di perusahaan startup.

Penelitian terdahulu menunjukkan bahwa hubungan antara kepribadian dan perilaku kerja inovatif tidak sepenuhnya dapat dipahami karena terdapat peran moderator seperti budaya (Wang, Begley, Hui, \& Cynthia, 2012), masa kerja (Woods, dkk., 2013) dan usia (Ng \& Feldman, 2013). Pada penelitian ini, yang akan digunakan sebagai moderator adalah masa kerja. Masa kerja merupakan moderator yang menarik untuk diteliti karena masa kerja mempunyai hubungan implikasi dengan beberapa faktor penting lain. Hal ini sesuai dengan apa yang disampaikan oleh Thoresen, Bradley, Bliese, dan Thoresen (2004) bahwa masa kerja merupakan variabel yang berkaitan erat dengan perbedaan tuntutan pekerjaan pada tahap awal bergabung dengan organisasi dan tahap lanjutan karyawan bekerja di organisasi. Perbedaan tersebut menurut Woods dkk. (2018) dapat berkaitan dengan konteks yang memicu munculnya perilaku kerja inovatif. Salah satu jenis perusahaan yang identik dengan perilaku kerja inovatif dan juga memiliki perbedaan tuntutan pada 
siklus awal dan lanjutan adalah perusahaan startup.

Pada konteks perusahaan startup, tuntutan pekerjaan sejalan dengan perkembangan perusahaan startup dari yang semula membangun sistem sampai melakukan pengembangan produk secara berkelanjutan (Areitio, 2016). Temuan sebelumnya dari Woods dkk. (2018) menunjukkan bahwa dengan bertambahnya waktu dan pengetahuan terkait pekerjaan, maka kecenderungan menciptakan ide dari orang-orang dengan tipe openness akan ditampilkan dengan lebih efektif, seperti pengetahuan terkait sistem, struktur, dan prosedur dapat menciptakan ide/inovasi untuk perbaikan dan pengembangan. Sebaliknya, ketika masa kerja bertambah, orang-orang dengan tipe kepribadian conscientiousness akan kurang berinovasi. Namun demikian, masih terdapat sedikit penelitian terkait hal tersebut, sehingga hipotesis tersebut menjadi menarik untuk diuji dalam penelitian ini. Oleh sebab itu, peneliti ingin melihat karakteristik tipe kepribadian seperti apa yang sesuai dengan perusahaan startup dan bagaimana dinamika antara tipe kepribadian dengan masa kerja karyawan dalam menghasilkan inovasi yang diharapkan.

\section{Perilaku Kerja Inovatif dan Tipe Kepribadian}

Perilaku kerja inovatif merupakan intensi untuk mencipta, memproduksi dan mengaplikasikan ide-ide baru dalam bekerja sesuai peran bagi kelompok maupun organisasi yang bertujuan untuk menguntungkan pekerjaan individu, kelompok, atau organisasi (Janssen, 2000). Perilaku kerja inovatif terdiri dari tiga aspek yaitu penciptaan ide (idea generation), promosi ide (idea promotion) dan realisasi ide (idea realization). Hammond dkk. (2011) melakukan meta-analisis prediktor dari perilaku kerja inovatif dan mengklasifikasikannya ke dalam tiga faktor, yaitu faktor individual (kepribadian: big five personality dan creative personality, demografis, motivasi, efikasi diri), faktor karakteristik pekerjaan (otonomi, kompleksitas pekerjaan, tekanan waktu, dan ekspektasi peran) dan faktor lingkungan (iklim organisasi dan kepemimpinan).

Mengacu pada trait theory, beberapa peneliti menyatakan bahwa individu memiliki potensi yang beragam dalam menghasilkan inovasi (Amabile, 1988; George \& Zhou, 2001; Hammond dkk., 2011; Niu, 2014; Raja \& Johns, 2010). Studi-studi terdahulu telah mengkaji pengaruh faktor-faktor big five personality (extraversion, agreeableness, 
186 I Jurnal Psikologi Talenta Vol. 4 No. 2

conscientiousness, neuroticism dan openness) terhadap perilaku kerja inovatif dan menemukan bahwa openness dan conscientiousness merupakan prediktor yang paling konsisten (Hsieh, Hsieh \& Wang, 2011; Munir \& Beh, 2016; Wang dkk., 2012; Woods dkk., 2018; Yesil \& Sozbilir, 2013).

Tipe kepribadian conscientiousness ditemukan memiliki hubungan dengan perilaku kerja inovatif (Kundu \& Roy, 2016; Hsieh dkk., 2011; Wang dkk., 2012) yang mana menurut Patterson dan Zibarras (2016) hubungan tersebut bersifat negatif. Di sisi lain, tipe kepribadian openness memiliki hubungan positif dengan perilaku kerja inovatif (Hammond dkk., 2011), yang menunjukkan bahwa ketika seseorang memiliki openness yang tinggi akan memiliki fleksibilitas dalam berpikir, memiliki rasa ingin tahu dan imajinatif (Costa \& McCrae, 1992). Individu dengan ciri tersebut terbuka pada pengalaman baru dan perubahan, yang mana terbukti konsisten untuk dapat berperan terhadap kemunculan inovasi (George \& Zhou, 2001).

- Hipotesis 1:

Tipe kepribadian conscientiousness berdampak terhadap perilaku kerja inovatif.
Hubungan Openness dan Conscientiouness

- Hipotesis 2:

Tipe kepribadian openness berdampak terhadap perilaku kerja inovatif.

Openness, Conscientiousness, Masa Kerja, dan Perilaku Kerja Inovatif

$\mathrm{Ng}$ dan Feldman

mengungkapkan bahwa masa kerja adalah seberapa lama seseorang bekerja pada suatu organisasi. Masa kerja merupakan variabel yang berkaitan dengan level individu yang dapat merepresentasikan perbedaan tuntutan pekerjaan (Thoresen dkk., 2004). Woods dkk. (2018) mengungkapkan bahwa masa kerja berkaitan erat dengan perubahan tuntutan pekerjaan yang dapat menjadi konteks yang memunculkan perilaku kerja inovatif.

Pada konteks perilaku kerja inovatif, tugas-tugas yang berkaitan dengan inovasi (menghasilkan ide baru, mencari dukungan terhadap ide, dan proses implementasi ide) lebih dirasakan sebagai tantangan oleh pegawai baru dibandingkan dengan pegawai dengan masa kerja lebih lama (Woods dkk., 2018). Karyawan dengan masa kerja lebih lama dapat memiliki keuntungan karena lebih memahami proses, sistem, struktur yang ada pada organisasi, yang dapat mendukung mereka untuk berinovasi dengan cara yang cukup selaras dengan konteks pekerjaan mereka (Zhou \& Oldham, 2001). Namun demikian, hal 
tersebut justru dapat berlaku sebaliknya. Pada orang-orang yang patuh terhadap prosedur, masa kerja yang lama justru dapat menghambat perilaku kerja inovatif, akan tetapi pada orang-orang yang kreatif, pengetahuan terkait organisasi dapat menjadi modal untuk membentuk ide-ide baru (Woods dkk., 2018).

Hubungan dan interaksi antara kepribadian dan masa kerja terhadap perilaku kerja inovatif dapat dijelaskan melalui trait activation theory. Teori tersebut menyatakan bahwa tuntutan pekerjaan merupakan salah satu konteks yang dapat mengaktifkan sifat-sifat kepribadian tertentu pada jenis pekerjaan dan tingkatan karier yang berbeda, lebih lanjut, sifat tersebut dapat meningkat atau berkurang seiring berjalannya waktu (Woods dkk., 2018). Dalam penelitian ini, kepribadian yang dimaksud yaitu conscientiousness dan openness.

\section{Orang-orang dengan} conscientiousness yang tinggi memiliki kecenderungan untuk lebih terorganisir, dan patuh terhadap peraturan (Costa \& McCrae, 1992; Judge, Rodell, Klinger, Simon, \& Crawford, 2013). Temuan sebelumnya (Woods dkk., 2018) menunjukkan bahwa dengan bertambahnya waktu, orang-orang dengan tipe kepribadian conscientiousness akan kurang berinovasi. Penelitian ini hendak memprediksi bahwa pada tahap awal suatu pekerjaan, orang-orang dengan conscientiousness yang tinggi akan lebih termotivasi untuk menunjukkan kinerjanya. Akan tetapi, Woods dkk. (2018) mengatakan bahwa ketika masa kerja meningkat, orang-orang tersebut belajar, bersosialisasi, dan beradaptasi dengan prosedur dan sistem dari organisasi. Hal ini membuat orang-orang dengan conscientiousness tinggi semakin patuh pada pekerjaan sehingga mengurangi inovasi mereka.

- Hipotesis 3 :

Pada masa kerja yang lebih pendek, conscientiousness yang tinggi diasosiasikan dengan perilaku kerja inovatif yang tinggi, sementara pada masa kerja yang lebih panjang, conscientiousness yang tinggi diasosiasikan dengan perilaku kerja inovatif yang rendah.

Orang-orang dengan openness yang tinggi merupakan orang-orang yang kreatif, imajinatif, dan memilih pekerjaan yang bervariasi daripada rutinitas (Costa \& McCrae, 1992; Judge dkk., 2013). Pada tahap awal dari suatu pekerjaan, potensi pengaruh dari kreativitas pada inovasi lebih terbatas karena orang-orang perlu memahami konteks dan tuntutan dari pekerjaan lebih dahulu sebelum dapat memahami informasi dan menghasilkan gagasan/ide (Woods dkk., 2018). 
Sebaliknya, ketika masa kerja meningkat dan pengetahuan terkait pekerjaan bertambah, maka kecenderungan menciptakan ide dari orang-orang dengan tipe openness akan ditampilkan dengan lebih efektif, seperti pengetahuan terkait sistem, struktur, prosedur dapat menciptakan ide/inovasi untuk perbaikan dan pengembangan. Dengan demikian, perilaku kerja inovatif akan meningkat pada orang-orang dengan tipe kepribadian openness yang memiliki masa kerja lebih lama.

- Hipotesis 4 :

Pada masa kerja yang lebih panjang, openness yang tinggi diasosiasikan dengan perilaku kerja inovatif yang tinggi.

\section{METODE}

Partisipan dan Prosedur

Total partisipan dalam penelitian ini adalah 105 orang karyawan startup dengan perbandingan jenis kelamin 56\% laki-laki dan $44 \%$ perempuan. Rentang usia partisipan berkisar antara 18 sampai dengan 31 tahun $(\mathrm{M}=24,37, \mathrm{SD}=3,5)$. Perbandingan jenjang pendidikan partisipan pada penelitian ini adalah 19\% lulusan SMA, 6\% lulusan D3, 68\% lulusan S1, dan 7\% lulusan S2.

Dalam penelitian ini, perbandingan masa kerja adalah 36\% kurang dari satu tahun, $47 \%$ 1-2 tahun, $16 \%$ lebih dari 3 tahun. Sektor startup tempat partisipan bekerja adalah (31\%) commerce, (28\%) lain-lain, (11,4\%) edutech, (10\%) fintech, $(8,5 \%)$ software, $(6,7 \%)$ marketing, dan (3\%) entertainment.

Data penelitian diambil menggunakan teknik non-probability samping dengan convenience sampling. Pengumpulan data dalam penelitian ini menggunakan kuesioner pada 105 orang, dengan pengisian secara offline berjumlah 85 orang sementara pengisian secara online berjumlah 20 orang. Pada bagian awal kuesioner terdapat kolom terkait dengan data demografis seperti jenis kelamin, usia, pendidikan, masa kerja dan sebagainya.

\section{Pengukuran}

Conscientiousness dan Openness diukur menggunakan The Big Five Personality Inventory (BFI) yang telah diterjemahkan dan diteliti (John dalam Ramdhani, 2012). Faktor conscientiousness $(\alpha=0,79)$ terdiri dari enam item dengan contoh item "Saya adalah seorang yang melakukan sesuatu dengan efisien", sementara faktor openness $(\alpha=0,79)$ terdiri atas enam item dengan contoh item "Saya adalah seorang yang sering dapat ide baru". Instrumen conscientiousness dan openness diukur menggunakan skala Likert dengan 
tujuh pilihan jawaban dari (1) sangat tidak setuju hingga (7) sangat setuju.

Pengukuran perilaku kerja inovatif dilakukan menggunakan The Innovative Work Behavior Scale yang dikembangkan oleh Janssen (2000) yang telah diadaptasi dalam penelitian Christianti (2015). Perilaku kerja inovatif $(\alpha=0,92)$ terdiri dari sembilan item dan diukur menggunakan skala Likert (1) tidak pernah sampai dengan (6) selalu. Salah satu contoh dari item perilaku kerja inovatif adalah "Mendapatkan persetujuan untuk ide-ide inovatif yang saya sampaikan".

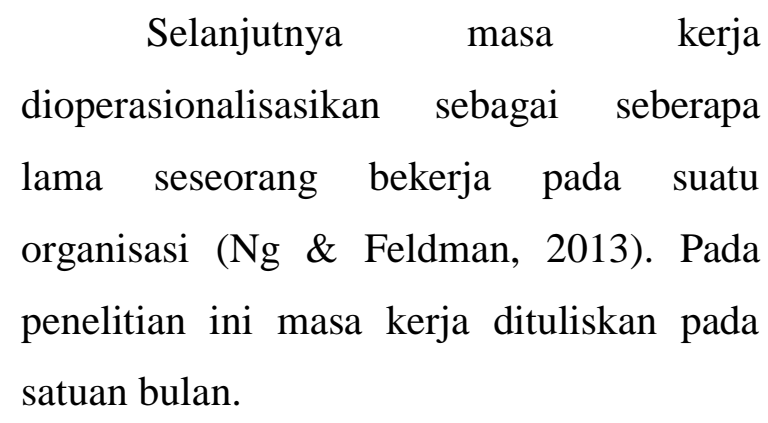

\section{HASIL}

Tabel 1 menunjukkan mean, standar deviasi dan interkorelasi antar variabel menggunakan olah data analisis deskriptif dan korelasi dari SPSS.

Tabel 1. Mean, Standar Deviasi, dan Matriks Korelasi Antar Variabel

\begin{tabular}{cccccc}
\hline Variabel & $\mathrm{M}$ & $\mathrm{SD}$ & 1 & 2 & 3 \\
\hline $1 . O P N$ & 31,89 & 4,82 & & & \\
$2 . C O N$ & 33,30 & 4,60 & $0,32^{* *}$ & & \\
$3 . I W B$ & 39,25 & 7,77 & $0,48^{* *}$ & $0,41^{* *}$ & \\
4.Tenure & 14,08 & 12,91 & 0,03 & 0,12 & $0,23^{*}$ \\
\hline
\end{tabular}

Note. $\quad N=105 . \quad O P N=$ Openness, CON=Conscientiousness, $\quad I W B=$ Innovative Work Behaviour. ${ }^{*}=p<0,01 .{ }^{* *}=p<0,05$

Tabel 2 menunjukkan hasil pengujian hipotesis menggunakan PROCESS for SPSS dari Hayes (2013). Pada penelitian ini, model 1 digunakan untuk melihat peran moderasi masa kerja pada hubungan conscientiousness dan perilaku kerja inovatif, serta peran moderasi masa kerja pada hubungan openness dan perilaku kerja inovatif.

Tabel 2. Regression Models

$$
\text { Prediktor } \quad \text { Model } 1
$$

(Luaran: Perilaku Kerja Inovatif)

B. SE T $p$

\begin{tabular}{lcccc}
\hline Conscientiousness & 0,55 & 0,21 & 2,55 & 0,01 \\
Masa kerja & $-0,15$ & 0,36 & $-0,4$ & 0,67 \\
$\begin{array}{l}\text { Conscientiousness } \\
\text { x Masa kerja }\end{array}$ & 0,00 & 0,01 & 0,74 & 0,45 \\
$\begin{array}{l}\text { Openness } \\
\text { Masa kerja }\end{array}$ & 0,66 & 0,17 & 0,38 & 0,00 \\
$\begin{array}{l}\text { Openness x Masa } \\
\text { Kerja }\end{array}$ & 0,01 & 0,01 & 0,99 & 0,32 \\
\hline
\end{tabular}

Note. $N=105 . D V=$ Dependent Variable

Hasil pada Tabel 2 menunjukkan bahwa conscientiousness secara signifikan mampu memprediksi perilaku kerja inovatif $(\mathrm{R}=0,55, \mathrm{t}(100)=2,55, \mathrm{p}<0,05)$. Besaran koefisien regresi conscientiousness yang diperoleh sebesar $0,55(\mathrm{p}<0,05)$ yang berarti setiap kenaikan satu unit pada conscientiousness akan meningkatkan 0,55 
pada skor perilaku kerja inovatif. Dengan kata lain, terdapat tipe kepribadian conscientiousness berperan karyawan terhadap perilaku kerja inovatif pada perusahaan startup sehingga Hipotesis 1 diterima.

Hasil analisis menunjukkan bahwa tidak terdapat efek interaksi yang signifikan dari conscientiousness dan masa kerja dalam memprediksi perilaku kerja inovatif $(\mathrm{R}=0,00, \mathrm{t}(100)=0,74, \mathrm{p}>0,05)$. Temuan ini menunjukkan tidak adanya peran moderasi masa kerja pada hubungan tipe kerpibadian conscientiousness karyawan dan perilaku kerja inovatif pada perusahaan startup sehingga Hipotesis 3 ditolak.

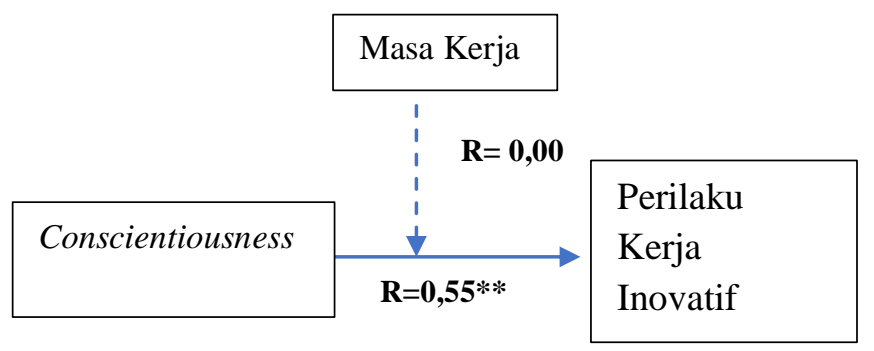

Gambar 1. Hasil Uji Model Kerangka

Konseptual 1

Hasil pengolahan data berikutnya menunjukkan bahwa secara statistik terdapat openness berperan secara signifikan untuk menjelaskan varians perilaku kerja inovatif $(R=0,66$, $\mathrm{t}(100)=0,38, \quad \mathrm{p}<0,05)$. Besaran koefisien regresi openness yang diperoleh sebesar $0,66(\mathrm{p}<0,05)$ yang berarti setiap kenaikan satu unit pada openness akan meningkatkan 0,66 pada skor perilaku kerja inovatif, dengan demikian Hipotesis 2 diterima. Hal ini menunjukkan bahwa pada perusahaan startup, karyawan dengan tipe kepribadian openness memiliki pengaruh terhadap perilaku kerja inovatif.

Analisis dari penelitian menunjukkan bahwa tidak terdapat efek interaksi yang signifikan dari openness dan masa kerja dalam memprediksi perilaku kerja inovatif $(\mathrm{R}=0,01, \quad \mathrm{t}(100)=0,99$, $\mathrm{p}>0,05)$. Dengan demikian, tidak terdapat peran moderasi masa kerja pada hubungan tipe kepribadian openness karyawan dan perilaku kerja inovatif pada perusahaan startup sehingga Hipotesis 4 ditolak.



Gambar 2. Hasil Uji Model Kerangka

Konseptual 2

\section{DISKUSI}

\section{Implikasi Teoritis}

Pertama, penelitian ini berkontribusi dalam menjelaskan peran dari tipe kepribadian kepada perilaku kerja inovatif. Penelitian ini memberikan pemahaman yang lebih baik bahwa tipe kepribadian 
karyawan (openness dan conscientiousness) merupakan tipe kepribadian yang penting dalam menciptakan perilaku kerja inovatif di perusahaan startup.

Hasil dari penelitian ini mendukung trait theory yang menyatakan bahwa individu mempunyai potensi yang beragam dalam menghasilkan inovasi (Amabile, 1988; George \& Zhou, 2001; Hammond dkk., 2011; Niu, 2014; Raja \& Johns, 2010). Hasil penelitian ini juga turut memperkuat temuan dari studi-studi empiris sebelumnya (George \& Zhou, 2001; Hammond dkk., 2011; Woods dkk., 2018, Yesil \& Sozbilir, 2013) yang menyatakan bahwa openness dan conscientiousness merupakan dua prediktor dari tipe kepribadian big five yang paling konsisten dalam memprediksi perilaku kerja inovatif.

Kedua, temuan dari penelitian tidak menunjukkan adanya peran masa kerja dalam hubungan antara tipe kepribadian baik openness maupun conscientiousness dan perilaku kerja inovatif pada karyawan perusahaan startup. Hasil ini menunjukkan teori trait activation yang menyatakan bahwa tuntutan pekerjaan merupakan salah satu konteks yang dapat mengaktifkan sifatsifat kepribadian tertentu pada suatu jenis pekerjaan (Woods dkk., 2018), yang mana tuntutan kerja dalam penelitian ini diwakili oleh masa kerja tidak berlaku pada karyawan di perusahaan startup.
Temuan ini sejalan dengan studi dari Ng dan Feldman (2013) yang tidak menemukan peran masa kerja sebagai moderator dari hubungan kepribadian dan perilaku inovatif. Masa kerja seharusnya mengindikasikan pemaparan seseorang terhadap pengalaman, pengetahuan, tuntutan kerja yang pada akhirnya memicu inovasi (Perkins, 1986). Pada penelitian ini, peran masa kerja yang tidak berfungsi dapat disebabkan oleh partisipan penelitian yang didominasi oleh karyawan di perusahaan startup yang kurang variatif dari segi masa kerja, dengan masa kerja terbanyak berada di range kurang dari dua tahun. Sampel tersebut memiliki range waktu pendek yang menunjukkan belum adanya pemaparan pada pengalaman maupun tuntutan kerja yang signifikan sehingga fungsi moderasi kurang terlihat dalam menciptakan perilaku inovatif pada penelitian ini.

\section{Implikasi Praktis}

Hasil dari penelitian menyarankan agar perusahaan startup perlu untuk mempertimbangkan dengan baik dimensidimensi kepribadian dari para pegawai mereka sehingga dapat meningkatkan inovasi pada perusahaan. Perusahaan startup dapat mengaplikasikan temuan dari penelitian pada saat proses rekrutmen dan seleksi. Perusahaan startup dapat mengembangkan strategi rekrutmen dan seleksi yang bertujuan untuk 
mengidentifikasi dan memilih pelamar yang memiliki potensi untuk berinovasi (Dhar, 2015).

Pihak perusahaan startup yang menghendaki perilaku kerja inovatif dari para karyawannya dapat mempekerjakan individu-individu yang dengan karakteristik kepribadian yang relevan dengan openness dan conscientiousness sehingga mereka dapat mengembangkan potensi dan kapasitas mereka dalam berinovasi.

\section{LIMITASI DAN SARAN}

Penelitian ini memiliki beberapa limitasi. Pertama, range masa kerja yang didapatkan dari sampel kurang bervariasi. Responden dalam penelitian ini memiliki range masa kerja yang didominasi dengan rentang di bawah dua tahun. Oleh sebab itu, pada penelitian selanjutnya dapat diupayakan masa kerja yang lebih beragam sehingga memungkinkan berfungsinya peran masa kerja sebagai moderator.

Faktor berikutnya adalah derajat kesamaan dari sampel. Sampel pada penelitian ini berasal dari berbagai sektor perusahaan startup seperti edutech, fintech, entertainment, dan commerce. Masingmasing sektor memiliki karakteristik masing-masing sehingga hal ini dapat berpengaruh terhadap karakteristik responden yang kurang begitu homogen. Sehingga, pada penelitian berikutnya dapat dilakukan pengambilan sampel pada sektor yang lebih spesifik.

Hal terakhir yaitu adanya common method bias yang disebabkan oleh pendekatan pengukuran pada variabel perilaku kerja inovatif. Pengukuran variabel perilaku kerja inovatif yang dilakukan dengan cara self-report berpotensi menimbulkan social desirability yang memungkinkan terjadinya bias pada jawaban responden karena responden menjawab pernyataan sesuai dengan apa yang diharapkan daripada apa yang sesuai dengan kenyataan di lapangan. Menurut Podsakoff, MacKenzie, Lee, dan Podsakoff (2003) salah satu langkah yang dapat dilakukkan adalah dengan melakukan pengukuran yang berasal dari dua sumber yang berbeda. Pengukuran perilaku kerja inovatif dapat dilakukan oleh atasan langsung dari responden sehingga hasil lebih objektif.

\section{KESIMPULAN}

Analisis yang dilakukan pada penlitian menunjukkan adanya pengaruh tipe kepribadian (conscientiousness dan openness) terhadap perilaku kerja inovatif karyawan pada perusahaan startup. Penelitian ini tidak menemukan adanya peran moderasi dari masa kerja pada hubungan antara tipe kepribadian (conscientiousness dan openness) dan 
perilaku kerja inovatif karyawan di perusahaan startup.

\section{DAFTAR PUSTAKA}

Amabile, T.M. (1988). A model of creativity and innovation in organizations. Research in Organizational Behaviour, 10, 123167.

Areitio, A. (2016). From idea to scaleup: Startup stages, understanding the milestones at every stage toward success. Retrieved from https://medium.com/theventurecity/f rom-idea-to-scaleup-startup-stagesa268799325d7

Bhaskara, I. (2016). Mengapa FoodPanda dan beberapa startup lain gagal?. Retrieved from https://tirto.id/mengapa-foodpandadan-beberapa-start-uo-lain-gagalbRbr

Bussgang, J. (2017). Are you suited for a start-up?. Retrieved from https://hbr.org/2017/11/are-yousuited-for-a-start-up

Costa, P.T. \& McCrae, R.R. (1992). Normal personality assessment in clinical practice: The NEO personality inventory. Psychological Assessment, 4, 5-13. http://dx.doi.org/10.1037/10403590.4.1.5

Dhar, R.L. (2015), The effects of high performance human resource practices on service innovative behaviour. International Journal of Hospitality Management, 51, 67-75. http://dx.doi.org/10.1016/j.ijhm.201 5.09 .002

Deen, A. (2017). What traits should you look for in your startup's first employees? Retrieved from https://articles.bplans.com/whattraits-should-you-look-for-in-yourstartups-first-employees/

George, J. M. \& Zhou, J. (2001). When openness to experience and conscientiousness are related to creative behavior: An interactional approach. Journal of Applied Psychology, 86, 513-524. http://dx.doi.org/10.1037/0021$\underline{9010.86 .3 .513}$

Hammond, M.M., Neff, N.L., Farr, J.L., Schwall, A.R., \& Zhao, X. (2011), Predictors of individual-level innovation at work: A metaanalysis. American Psychological Association. Psychology of Aesthetics, Creativity, and the Arts, 5 , 90-105. http://dx.doi.org/10.1037/a0018556

Hsieh, H., Hsieh, J., \& Wang, I. (2011). Linking personality and innovation: The role of knowledge management. World Transactions on Engineering and Technology Education, 9, 3841.

Janssen, O. (2000). Job demands, perceptions of effort-reward fairness and innovative work behavior. Journal of Occupational and Organizational Pychology, 73, 287302.

https://doi.org/10.1348/0963179001 $\underline{67038}$

Judge, T.A., Rodell, J.B., Klinger, R.L., Simon, L.S., \& Crawford, E.R. (2013). Hierarchical representations of the five-factor model of personality in predicting job performance: Integrating three organizing frameworks with two theoretical perspectives. The Journal of Applied Psychology, 98, 875-925. http://dx.doi.org/ 10.1037/a0033901 
Kumar, K., \& Bakshi, A. (2010). The five factor model of personality and organizational commitment: Is there any relationship? Humanity and Social Sciences Journal, 5, 25-34.

Kundu, A. \& Roy, D.D. (2016). Innovative work behaviour of school teachers: role of belief for innovative and personality patterns. Journal of Organization and Human Behavior, 5 (1), http://dx.doi.org/ $\underline{10.21863 / \mathrm{johb} / 2016.5 .1 .024}$

Munir, R., \& Beh, L. (2016). Do Personality traits matter in fostering innovative work behavior? The Social Sciences, 11, 4393-4398. http://dx.doi.org/

$\underline{10.3923 / \text { sscience. } 2016.4393 .43}$ $\underline{98}$

Ng, T.W., \& Feldman, D.C. (2013), A meta-analysis of the relationships of age and tenure with innovation-related behaviour. Journal of Occupational and Organizational Psychology, 86, 585-616. http://dx.doi.org/10.1111/joop.1203 $\underline{1}$

Niu, H.J. (2014). Is innovation behaviour congential? Enhancing job satisfaction as a moderator. Personnel Review, 43, 288-301. http://dx.doi.org/10.1108/PR-12$\underline{\text { 2012-0200 }}$

Patel, N. (2015). 90\% of startups fail: Here's what you need to know about the 10\%. Retrieved from https://www.forbes.com/sites/neilpat el/2015/01/16/90-of-startups-willfail-heres-what-you-need-to-knowabout-the-10/\#5d9d17046679

Patterson, F. \& Zibarras, L.D. (2016). Selecting for creativity and innovation potential: Implications for practice in healthcare education.

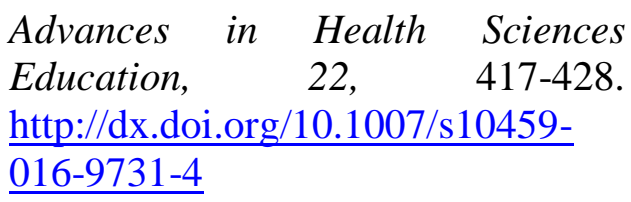

Perkins, D. N. (1986). Thinking frames. Educational Leadership, 43, 41-10

Podsakoff, P. M., MacKenzie, S. B., Lee, J., \& Podsakoff, N. P. (2003). Common method biases in behavioral research: A critical review literature and recommended remedies. Journal of Applied Psychology, 88, 879-903.

http://dx.doi.org/10.1037/00219010.88.5.879

Potsangbam, C. (2017). Adaptive performance in VUCA era - where is research doing?.International Journal of Management, , 99-108.

Raja, U., \& Johns, G. (2010). The joint effects of personality and job scope on in-role performance citizenship behaviors, and creativity, Human Relations, 63, 981-1005. https://dx.doi.org/10.1177/00187267 $\underline{09349863}$

Raghuramapatruni, R. \& Kosuri S. (2017). The straits of success in a VUCA world. Journal of Business and Management, 16-22.

Ramdhani, N. (2012). Adaptasi bahasa dan budaya inventori Big Five. Jurnal Psikologi, 39, 189-207.

Salamzadeh, A., \& Kesim, H. K. (2015). Startup companies: Life cycle and challenges. Proceedings from EEE: The $4^{\text {th }}$ International Conference on Employment, Education, and Entrepreneurship. Belgia: Serbia.

Thoresen, C.J., Bradley, J.C., Bliese, P.D., \& Thoresen, J.D. (2004), The Big Five personality traits and 
individual job performance growth trajectories in maintenance and transitional job stages. Journal of Applied Psychology, 89, 835-853, http://dx.doi.org/10.1037/00219010.89.5.835

Start Up Ranking. (2018). Startups ranking per country. Retrieved from https://www.startupranking.com/cou ntries.

Wang, H., Begley, T., Hui. C., \& Cynthia, L. (2012). Are the effects of conscientiousness on the contextual and innovative performance context specific? Organizational culture as a moderator. The International Journal Of Human Resource Management, 23, 174-189. http://dx.doi.org/10.1080/09585192. $\underline{2011.561246}$

Woods, S.A., Lievens, F., De Fruyt, F. \& Wille, B. (2013). Personality across working life: The longitudinal and reciprocal influences of personality on work. Journal of Organizational Behavior, 34(S1), S7-S25. http://dx.doi.org/0.1002/job.1863

Woods, S.A., Mustafa, M.J., Anderson, N., \& Sayer, B. (2018). Innovative work behavior and personality traits: Examining the moderating effects of organizational tenure. Journal of Managerial Psychology, 33, 29-42. http://dx.doi.org/10.1108/JMP-012017-0016

Yesil, S., \& Sozbilir, F. (2013). An empirical investigation into the impact of personality on individual innovation behavior in the workplace. Procedia-Social and Behavioral Sciences, 28, 540-551 http://dx.doi.org/10.1016/j.sbspro.20 13.06.474
Zhou, J., \& Oldham, G.R. (2001), Enhancing creative performance: effects of expected developmental assessment strategies and creative personality. The Journal of Creative Behaviour, 35, 151-167. http://dx.doi.org/10.1002/j.21626057.2001.tb01044.x 